\title{
A High Serum-Ascites Albumin Gradient and Mediastinal Fibrosarcoma: A Case Report
}

\author{
Ahmad Hormati ${ }^{1}$, Maryam Jameshorani ${ }^{2, *}$, Saeid Sarkeshikian ${ }^{1}$, \\ Mohammad Reza Ghadir ${ }^{3}$, Faezeh Alemi ${ }^{4}$
}

1. Assistant Professor of Gastroenterology, Research Center for Gastroenterology and Hepatology, Qom University of Medical Sciences, Qom, Iran

2. Assistant Professor of Internal Medicine, Metabolic Disease Research Center, Zanjan University of Medical Sciences, Zanjan, Iran

3. Associate Professor of Gastroenterology, Research Center for Gastroenterology and Hepatology, Qom University of Medical Sciences, Qom, Iran

4. General Practitioner, Research Center for Gastroenterology and Hepatology, Qom University of Medical Sciences, Qom, Iran

* Corresponding Author:

Maryam Jameshorani, MD

Metabolic Disease Research Center, Zanjan University of Medical Sciences, Zanjan, Iran

Telefax: + 982433770814

Email: dr.shirinjameshorani@yahoo.com

Received: 10 Jun. 2018

Accepted: 02 Sep. 2018

\section{ABSTRACT}

Accumulation of free fluid in the peritoneal cavity is called ascites. The first step in identifying its etiology is to determine the serum-ascites albumin gradient (SAAG). According to this parameter, a high SAAG is regarded as a gradient greater than $1.1 \mathrm{~g} / \mathrm{dL}$. This condition has some differential diagnoses such as liver cirrhosis, Budd-Chiari syndrome, heart failure, and idiopathic portal fibrosis.

In the present article, we present a young man with abdominal distention due to a high SAAG. Further evaluation of the abdominal and thoracic cavity revealed a mass in the posterior mediastinum, which had compressed the inferior vena cava and left atrium and led to Budd-Chiari syndrome. Evaluation of the biopsy sample showed fibrosarcoma.

Mediastinal fibrosarcomas, though rare, should be considered in the differential diagnosis of mediastinal masses.

\section{KEYWORDS:}

Ascites, Budd-Chiari Syndrome, Fibrosarcoma

Please cite this paper as:

Hormati A, Jameshorani M, Sarkeshikian S, Ghadir MR, Alemi F. A High Serum-Ascites Albumin Gradient and Mediastinal Fibrosarcoma: A Case Report. Midddle East J Dig Dis 2018;10:258-262. doi: 10.15171/mejdd.2018.120.

\section{INTRODUCTION}

The peritoneal cavity is typically filled with a small amount $(<50 \mathrm{~mL})$ of serous and slippery fluid, which is a rich source of protein $(40 \mathrm{~g} / \mathrm{L})$. Free fluid accumulation in the cavity is called ascites. It must be remarked that abscess formation or cystic accumulation are not considered here. ${ }^{1}$

There are several ascitic fluid tests. Nevertheless, a rational determination of the order of the tests should be made according to the clinical setting of each patient. The serum-ascites albumin gradient (SAAG), a parameter dependent on hydrostatic and oncotic pressure gradients between the intra-vascular area and serous cavities, is the difference between the gradient of the albumin concentration in the serum and ascitic fluid.

Liver cirrhosis, Budd-Chiari syndrome, heart failure, and idiopathic portal fibrosis can cause a SAAG $>1.1 \mathrm{~g} / \mathrm{dL} .^{2}$ The obstruction of hepatic venous outflow causes Budd-Chiari syndrome. This obstruction is the result of mass or thrombi in the large hepatic veins and venae cavae 
Table 1: The patient's blood test results

\begin{tabular}{|c|c|c|c|c|c|c|c|c|c|c|}
\hline Day of admission & PLT $^{1}$ & $\mathrm{WBC}^{2}$ & $\mathbf{R B C}^{3}$ & $\mathbf{H b}^{4}$ & $\mathrm{MCV}^{5}$ & $\mathbf{A L T}^{6}$ & $\mathbf{A S T}^{7}$ & $\mathbf{A L P}^{8}$ & $P T^{9}$ & PTT $^{10}$ \\
\hline $1^{\text {st }}$ & 196000 & 6000 & $5.83 * 10^{6}$ & 13.8 & 76.8 & 105 & 56 & 303 & 12.9 & \\
\hline $2^{\text {nd }}$ & 263000 & 9700 & $5.93 * 10^{6}$ & 14.1 & 76.5 & & & & & \\
\hline $7^{\text {th }}$ & 349000 & 9300 & $5.22 * 10^{6}$ & 11.7 & 78.1 & & & & & \\
\hline $10^{\text {th }}$ & 233000 & 5500 & $5.24 * 10^{6}$ & 12.8 & 80.3 & 33 & 32 & 338 & 13.2 & 46 \\
\hline
\end{tabular}

Table 2: The patient's blood test results

\begin{tabular}{|c|c|c|c|c|}
\hline Day of admission & $\mathrm{Na}^{+1}$ & $\mathbf{K}^{+2}$ & Urea $^{3}$ & $\mathrm{Cr}^{4}$ \\
\hline $3^{\text {rd }}$ & 136 & 4.5 & 20 & 0.8 \\
\hline $7^{\text {th }}$ & 159 & 4.6 & & \\
\hline $10^{\text {th }}$ & 140 & 4.5 & 31 & 0.9 \\
\hline
\end{tabular}

1- Sodium, 2- potassium, 3-Urea, 4-Creatine

in most cases. This syndrome has the following symptoms: hepatomegaly, splenomegaly, edema, and ascites. ${ }^{3}$

Fibrosarcoma or fibroblastic sarcoma is a malignant mesenchymal tumor. It is derived from fibroblast cells. These are highly malignant tumors except when they extend to the skin and tend to infiltrate the surrounding tissues and relapse after removal. ${ }^{4-7}$ Intrathoracic fibrosarcomas are found as endobronchial masses in the main or lobar bronchi. When they affect the lungs, patients present solitary or multiple nodules. Fibrosarcomas are well marginated nodules. Computed tomography (CT) indicates that these lesions are homogeneous nodules with no calcification. ${ }^{8}$

\section{CASE REPORT}

A 30-year-old man presented with abdominal distention and inflation lasting for 6 weeks. On his admission to hospital, his physiological data were recorded: blood pressure $=110: 70 \mathrm{mmHg}$, pulse rate $=75$, respiratory rate $=18$, body temperature $=$ $36.7^{\circ} \mathrm{C}$, and $\mathrm{O}_{2}$ saturation $=96 \%$. He had a history of dry coughs and asthma and was allergic to gas oil. In lab test, a high SAAG and high polymorphonuclear (PMN) cells were observed. However, there was no noticeable lymphadenopathy. The patient suffered from pitting edema of the lower extremity for 5 weeks. He had undergone surgery on the right tibia and had platinum implantation. His drug history included domperidone, dimethicone, salbutamol spray, fluticasone, and psyllium powder. Blood samples were collected in hospital for further tests. The results are shown in tables 1 and 2 .

The tests on ascitic fluid (fluid effusion in the peritoneal cavity) showed the following: red color, semi-clear appearance, $\mathrm{WBC}=200 \mathrm{cmm}, \mathrm{RBC}=$ $31500 \times 10^{12}$ cells per liter, $\mathrm{Hb}: 10 \mathrm{~g} / \mathrm{dl} \mathrm{PMN}=70 \%$, lymphocytes $=30 \%$, ascites $\mathrm{LDH}=180 \mathrm{U} / \mathrm{L}$, ascites albumin $=1.9 \mathrm{~g} / \mathrm{dL}$, and amylase $=12 \mathrm{~g} / \mathrm{dL}$. The ascitic fluid cytology smear revealed the following: $\mathrm{WBC}=2-3$, hemorrhagic background, a few BLAND-looking mesothelial cells, and a few mixed inflammatory cells.

Results of the Doppler sonography of the right and left lower extremity veins showed the signs of thrombosis in all pathways including common and superficial femoral and also popliteal veins so that there was no sign of blood flow there. The left major and minor saphenous veins were compressible, but there was no sign of blood flow there either because of thrombosis in their deep pathways. Furthermore, thrombosis had developed to the inferior vena cava (IVC) and external and common iliac veins and had blocked their lumens completely. The overall results of the sonography showed extensive thrombophlebitis of the right and left lower extremities, which had been propagated to the IVC.

Spiral abdominopelvic CT with intravenous (IV) and oral contrast showed that the liver, gall bladder, 


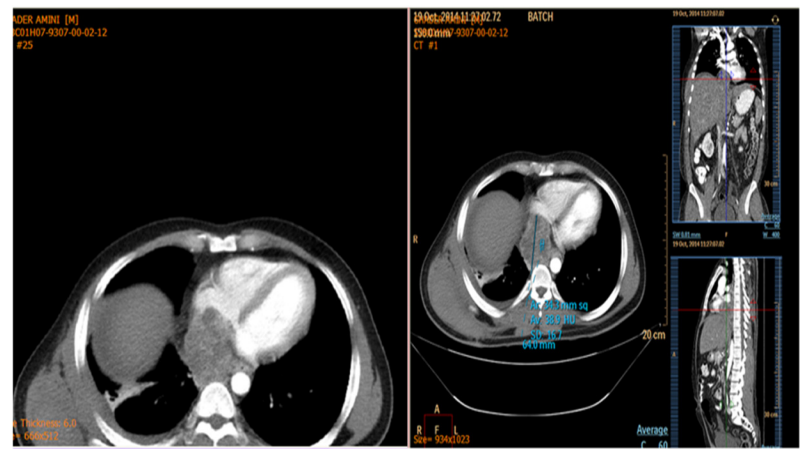

Fig.1: The mediastinal mass that has compressed the right atrium
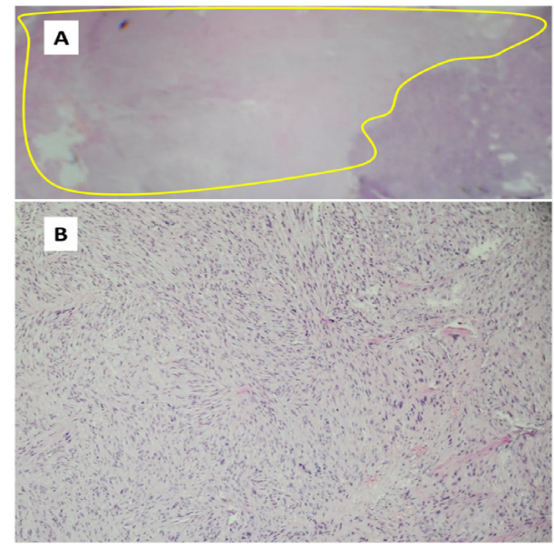

Fig.3: a. Extensive tumor necrosis: $>\mathbf{5 0} \%$ of tumor tissue (encircled); b. Tumor composed of spindle cells arranged in fascicles and storiform pattern

and bile ducts were normal in size. The spleen and kidneys were also normal in size. There was no evident retroperitoneal and para-aortic lymphadenopathy. Only minimal ascitic fluid was seen in the abdominal cavity.

The chest CT with IV contrast showed a soft tissue with a lobulated mass $(47 \times 62 \mathrm{~mm})$ in the right posterior mediastinum with heterogeneous enhancement, which had caused compression on the IVC and right atrium, with so hyperdense small foci seen in the mass (Figure 1). Furthermore, there were some small nodular opacities in the lungs, especially in basal segments, one on the right side (7 $\mathrm{mm})$ and the other on the left side $(5 \mathrm{~mm})$ associated with at least two small $(6 \mathrm{~mm})$ nodules adjacent to the left wall of the heart (LV). Ascites in upper abdominal images was due to a posterior mediastinal mass, such as lymphoma, metastases, neural tumor

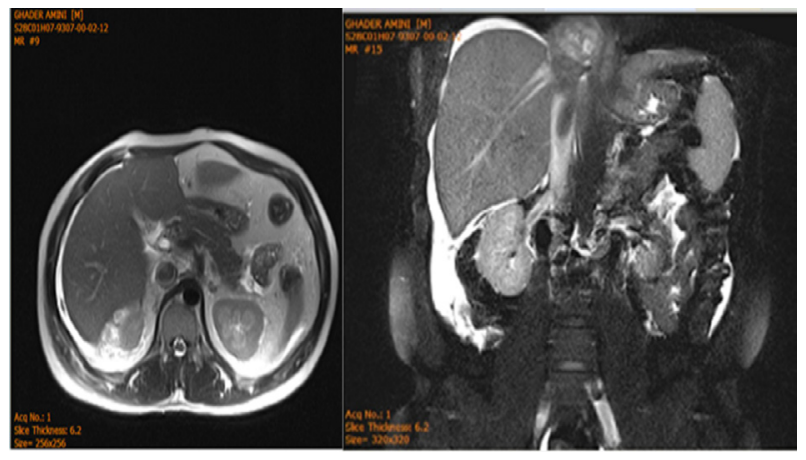

Fig.2: Thrombosis can be seen in the inferior vena cava on MRI

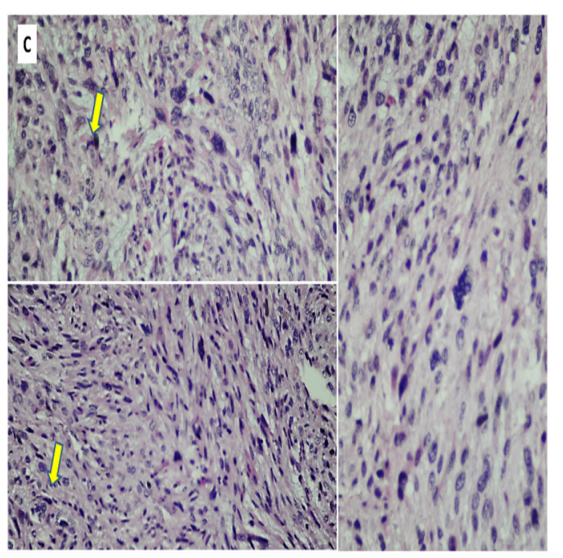

Fig.4: Malignant spindle cells with pleomorphic hyperchromatic nuclei, some multinucleated forms and mitoses (arrows).

(Figure 2). Hence, a biopsy was recommended.

Biopsy sample was taken from the posterior mediastinal mass, which had affected the phrenic nerve. In a microscopic view, there were multiple fragments of the tumor tissue with extensive areas of necrosis, which had occupied over $50 \%$ of the tissue (Figure 3). The tumor was composed of malignant spindle cells, arranged in fascicles and a storiform pattern and displayed pleomorphic and hyperchromatic nuclei (Figure 4). Some multinucleated tumoral giant cells were noted. The mitotic rate was about 4-5/10 HPF (High power field). The stroma was variably fibrotic and myxoid. Moreover, pathological diagnosis of the mass suggested grade 2 (FNCLCC: Fédération Nationale des Centres de Lutte Contre le Cancer grading system) soft tissue sarcoma or possibly fibrosarcoma. 


\section{DISCUSSION}

Ascites formation is the result of a series of anatomical, pathophysiological, and biochemical changes. The specific causes of ascites can be either associated with portal hypertension (cirrhotic ascites) or unrelated to it (non-cirrhotic ascites). In patients with cirrhosis, ascites is a consequence of sinusoidal portal hypertension, which can change the capillary pressure, permeability, and accumulation of fluid in the abdominal cavity. This is called transudation. Another mechanism of ascites formation is exudation in which ascites formation is secondary to increased vascular permeability due to the inflammatory process, tumoral invasion, or traumatic damage to the peritoneum or intraperitoneal organs. ${ }^{1,9}$

A SAAG cut off value of $11 \mathrm{~g} / \mathrm{L}$ has been shown to distinguish patients in whom ascites is secondary to portal hypertension from those without portal hypertension. A high gradient $(>1.1 \mathrm{~g} / \mathrm{dL})$ shows the portal hypertension cause of ascites, either related to liver pathology or not, with about $97 \%$ accuracy. ${ }^{10}$ This is because of an increase in the hydrostatic pressure in the vascular system of the liver, which leads to water permeation into the peritoneal cavity but proteins such as albumin, remain in the vessels. ${ }^{11}$

In the present patient, the tumor was located in the posterior mediastinal area so that it compressed the IVC and caused Budd-Chiari syndrome. Mediastinal fibrosarcomas approximately occur between the 19 to 73 years of age. The incidence of this disease is the same between male and female sexes. ${ }^{12}$ There is no difference among mediastinal compartments. Evaluation of these tumors can be made using various tests such as chest radiography, conventional radiography, CT angiography, bronchoscopy, sputum studies, and skin tests. ${ }^{13}$ The thoracotomy and biopsy of the mediastinal mass is the most common method. Signs and symptoms depend on the size and location of the mass and may be variable. Further evaluation should be considered for symptomatic patients with even non-specific, radiological abnormalities. ${ }^{14}$

Intrathoracic fibrosarcomas are detected as an endobronchial mass in the main or lobar bronchi. When the tumors affect the lungs, patients present with solitary or multiple nodules. Fibrosarcomas are well marginated nodules. CT shows that these lesions are homogeneous nodules with no calcification. ${ }^{8}$

Some studies about SAAG have been done in different country with regard to alcoholic cirrhosis, but studies on nonalcoholic cirrhosis are inadequate. In one study, 50 patients of cirrhosis of various etiologies were selected. A relation was studied between SAAG and portal hypertensive changes in the upper gastrointestinal tract like esophageal and stomach varices, and gastropathy. As the SAAG increases, the percentage of patients having large-sized varices rised too, but such increase was not seen in small- and medium-sized varices so concluded that Serum ascites albumin gradient value is weakly related to the extent of portal hypertension in patients with liver cirrhosis. $^{15}$

The treatment of the chest wall and mediastinal lesions is resection. Postoperative radiotherapy can be considered if surgical margins are available or if the tumor is not completely resectable. ${ }^{16}$ Larger masses tend to recur locally and have a poor prognosis whereas small nodules have the likelihood of metastases. ${ }^{8}$

Variety in clinical presentations, different locations of the mass, morphological features, and imaging characteristics can be helpful in determining the appropriate diagnosis. ${ }^{15}$ Nevertheless, for a definite histological diagnosis, it is essential to have exploratory thoracotomy with the biopsy of the mass. ${ }^{17}$

\section{CONCLUSION}

Mediastinal fibrosarcomas are rarely considered in the differential diagnosis of mediastinal masses. Different histological types of sarcomas are not distinguishable in radiological studies. Any radiological evaluation should be confirmed using biopsy sampling. Due to its rare occurrence, fibrosarcoma is usually an exclusive diagnosis. However, appropriate evaluations are required for an early diagnosis, especially in malignant lesions.

\section{ETHICAL APPROVAL}

There is nothing to be declared.

\section{CONFLICT OF INTEREST}

The authors declare no conflict of interest related to this work.

\section{REFERENCES}

1. Runyon BA. Approach to the patient with ascites. In: Yamada T,Alpers DH, Kaplowitz N. Textbook of 
Gastroenterology, Vol. 1. Philadelphia: Lippincott, Williams and Wilkins: 2003:948-72.

2. Runyon BA, Practice Guidelines Committee, American Association for the Study of Liver Diseases (AASLD). Management of adult patients with ascites due to cirrhosis. Hepatology 2004;39:841-56. doi:10.1002/hep.20066.

3. Uriz J, Cárdenas A, Arroyo V. Pathophysiology, diagnosis and treatment of ascites in cirrhosis. Baillieres Best Pract Res Clin Gastroenterol 2000;14:927-43. doi:10.1053/bega.2000.0139.

4. Fraser RS, Muller NL, Colman N, Pare PD. Anterior mediastinal masses. In: Fraser and Pare's diagnosis of diseases of the chest. $4^{\text {th }}$ ed. Philadelphia, Pa: Saunders, 1999; 2875-2937.

5. Janigan DT, Husain A, Robinson NA. Cardiac angiosarcomas. A review and a case report. Cancer 1986;57:852-9.

6. Araoz PA, Eklund HE, Welch TJ, Breen JF. CT and MR imaging of primary cardiac malignancies. Radiographics 1999;19:1421-34. doi:10.1148/ radiographics.19.6.g99no031421.

7. Sethi GK, Slaven JE, Kepes JJ, Pugh D, Thal AP. Primary sarcoma of the pulmonary artery. $J$ Thorac Cardiovasc Surg 1972;63:587-93.

8. Pachter MR, Lattes R. Mesenchymal tumors of the mediastinum. I. Tumors of fibrous tissue, adipose tissue, smooth muscle, and striated muscle. Cancer 1963;16:74-94.

9. Enck RE. Malignant ascites. Am J Hosp Palliat Care 2002;19:7-8. doi:10.1177/104990910201900101.

10. Runyon BA, Montano AA, Akriviadis EA, Antillon MR, Irving MA, McHutchison J. The serum-ascites albumin gradient is superior to the exudate - transudate concept in the differential diagnosis of ascites. Ann Intern Med 1992;117:215-20.

11. Yetkin O, Tek I, Kaya A, Ciledag A, Numanoglu N. A simple laboratory measurement for discrimination of transudative and exudative pleural effusion: Pleural viscosity. Respir Med 2006;100:1286-90. doi: 10.1016/j.rmed.2005.10.010.

12. Guccion JG, Rosen SH. Bronchopulmonary leiomyosarcoma and fibrosarcoma: a study of 32 cases and review of the literature. Cancer 1972;30:836-47.

13. Barua NR, Patel AR, Takita H, Jennings EC. Fibrosarcoma of the Mediasthum. J Surg Oncol 1979;12:11-7.

14. Gladish GW, Sabloff BM, Munden RF, Truong MT, Erasmus JJ, Chasen MH. Primary Thoracic Sarcomas. Radiographics 2002;22:621-37. doi:10.1148/ radiographics.22.3.g02ma17621.

15. Shahed FHM, Mamun-Al-Mahtab, Rahman S. The Evaluation of Serum Ascites Albumin Gradient and Portal Hypertensive changes in Cirrhotic Patients with Ascites. Euroasian $J$ Hepatogastroenterol 2016;6:8-9. doi:10.5005/jp-journals-10018-1157.
16. Correlation Conferences in Radiology, Pathology, Mediastinal Mass. N Y State J Med 1971;71:2867-71.

17. Takeuchi J, Takada A, Hasumura Y, Matsuda Y, Ikegami P. Budd-Chiari syndrome associated with obstruction of the inferior vena cava. A report of seven cases. Am J Med 1971;51:11-20. 